\title{
Anandamide Depresses Glycinergic and GABAergic Inhibitory Transmissions in Adult Rat Substantia Gelatinosa Neurons
}

\author{
Yasuhiko Kawasaki, Tsugumi Fujita, Kun Yang, Eiichi Kumamoto* \\ Department of Physiology, Saga Medical School, Saga, Japan \\ Email: "kumamote@cc.saga-u.ac.jp
}

Received 27 January 2015; accepted 2 March 2015; published 5 March 2015

Copyright (C) 2015 by authors and Scientific Research Publishing Inc.

This work is licensed under the Creative Commons Attribution International License (CC BY). http://creativecommons.org/licenses/by/4.0/

(c) (7) Open Access

\begin{abstract}
Cannabinoid CB1 receptors have been found in the superficial dorsal horn of the spinal cord, particularly the substantia gelatinosa (SG), which is thought to play a pivotal role in modulating nociceptive transmission. Although cannabinoids are known to inhibit excitatory transmission in SG neurons, their effects on inhibitory transmission have not yet been examined fully. In order to know further about a role of cannabinoids in regulating nociceptive transmission, we examined the effects of cannabinoids on inhibitory transmissions in adult rat SG neurons using whole-cell voltage-clamp recordings. Anandamide $(10 \mu \mathrm{M})$ superfused for 2 min reduced glycinergic and GABAergic electrically-evoked inhibitory postsynaptic current (IPSC) amplitudes; these actions persisted for more than 6 min after washout. Similar actions were produced by cannabinoid-receptor agonist WIN55,212-2 (5 $\mu \mathrm{M})$ and 2-arachidonoyl glycerol (20 $\mu \mathrm{M})$. The evoked IPSC amplitudes reduced by anandamide recovered to the control level following superfusion of CB1-receptor antagonist SR141716A (5 $\mu \mathrm{M})$. A ratio of the second to first evoked IPSC amplitude in pairedpulse experiments was increased by anandamide $(10 \mu \mathrm{M})$. The frequencies of glycinergic and GABAergic spontaneous IPSCs were reduced by anandamide $(10 \mu \mathrm{M})$ without a change in their amplitudes. It is concluded that cannabinoids depress inhibitory transmissions in adult rat SG neurons by activating CB1 receptors in nerve terminals. This action could contribute to the modulation of nociceptive transmission by cannabinoids.
\end{abstract}

\section{Keywords}

Spinal Dorsal Horn, Cannabinoid, CB1 Receptor, IPSC, Patch-Clamp, Pain

\footnotetext{
"Corresponding author.
} 


\section{Introduction}

Cannabinoids play an important role in a variety of physiological phenomena including antinociception (for review see [1]-[4]). Cannabinoid receptors are classified into two subtypes, CB1 and CB2, both of which are Gprotein coupled receptors [1]. When administered intrathecally, cannabinoids produce antinociception in acute pain models through the activation of the cannabinoid receptors [1] [3] [4]. For instance, applying the prototypical cannabinoid $\Delta^{9}$-tetrahydrocannabinol resulted in antinociception in the tail-flick test in adult rats [5]. A mixed CB1/CB2 receptor agonist WIN55,212-2 (WIN-2) produced a similar antinociceptive effect [6]. Such behavioral results are possibly due to the activation of the CB1 receptor in the spinal dorsal horn, because expression of this receptor has been demonstrated there by in situ hybridization [7], agonist binding [8] and immunohistochemistry [9]-[12]. A selective CB1-receptor antagonist SR141716A enhanced nociceptive responses of rat spinal dorsal horn neurons [13].

The superficial dorsal horn of the spinal cord, particularly the substantia gelatinosa (SG, lamina II of Rexed), is thought to play an important role in regulating nociceptive transmission from the periphery through the modulation of synaptic transmissions in SG neurons (for review see [14]-[16]). In support of this idea, glutamatergic excitatory transmission to SG neurons through primary-afferent fibers is inhibited by various endogenous substances including opioids [17], serotonin [18], nociceptin [19], noradrenaline [20], adenosine [21] and galanin [22] which are thought to act as analgesics in the spinal dorsal horn (for review see [15]). This idea appears to be applied also to the cannabinoid-mediated antinociception, because cannabinoids inhibit glutamatergic transmission in rat SG neurons [23] [24]. A similar inhibition of glutamatergic transmission by cannabinoids has been reported in the spinal trigeminal pars caudalis SG [25].

Glycinergic and GABAergic inhibitory interneurons in the SG are involved in polysynaptic pathways originating in primary-afferent terminals ([26]; for review see [14] [16]), and probably serve to modulate nociceptive transmission [27] [28].Consistent with this idea, the lack of GABA-synthesizing enzyme [29] and also an inhibition of $\mathrm{K}^{+}-\mathrm{Cl}^{-}$exporter KCC2 expression, which causes inhibitory synaptic response to be excitatory [30], in the rat spinal dorsal horn lead to nociception. There is a difference among endogenous analgesics in modulating inhibitory transmission mediated by the interneurons. For example, noradrenaline [31], acetylcholine ([32]-[34]), serotonin [35] and oxytocin ([36] [37]) enhanced the inhibitory transmission, possibly contributing to antinociception. On the other hand, the inhibitory transmission was unaffected by opioids ([17]), nociceptin ([19]) and galanin ([22]) while being inhibited by adenosine ([38]). The latter action may contribute to nociception rather than antinociception. Depression of inhibitory transmission by cannabinoids has been reported in various CNS regions including the corpus striatum ([39]), the hippocampal CA1 ([40] [41]), the spinal trigeminal pars caudalis SG ([42]) and the substantia nigra pars reticulata (SNR; [43]). However, the effects of cannabinoids on inhibitory transmission in the spinal cord SG have not yet been examined fully. There are no reports about the effects of cannabinoids on glycinergic transmission except for the studies by Jennings et al. [42] and Pernía-Andrade et al. [44]. Although the latter study revealed an inhibition by WIN-2 of GABAergic and glycinergic transmissions, this was performed in superficial dorsal horn neurons of young ( 1 - 3 weeks old) mice. An inhibition of inhibitory transmission by cannabinoids may exhibit a developmental change, as seen in the oxytocin actions in rat SG neurons. Oxytocin enhanced spontaneous GABAergic but not glycinergic inhibitory transmission in young (2 - 4 weeks old) rats ([36]) whereas facilitating both of the inhibitory transmissions in adult (6 - 8 weeks old) rats ([37]). The highest concentration of a precursor of an endocannabinoid $N$-arachidonoylethanolamide (anandamide; ANA) is found in the spinal cord [45]. ANA activates the CB1 receptor more effectively than the CB2 receptor [1]. In the present study, we investigated the effects of ANA on glycinergic and GABAergic inhibitory transmissions in SG neurons of adult rat spinal cord slices by using the whole-cell patchclamp technique. A part of this study has been reported in abstract form [46].

\section{Materials and Methods}

All animal experiments were approved by the Animal Care and Use Committee of Saga University, and were conducted in accordance with the Guiding Principles for the Care and Use of Animals in the Field of Physiological Science of the Physiological Society of Japan. All efforts were made to minimize animal suffering and the number of animals used.

\subsection{Slice Preparations}

Spinal cord slices from adult rats were prepared as described previously [20] [38] [47]. In brief, adult Sprague- 
Dawley rats (7 - 8 weeks old; 250 - 300 g) were anesthetized with urethane (1.5 g/kg body weight, i.p.) and a laminectomy was performed to extract a lumbosacral spinal cord segment. The spinal cord was quickly immersed in ice-cold $\left(1^{\circ} \mathrm{C}-3^{\circ} \mathrm{C}\right.$ ) Krebs solution (in mM: $\mathrm{NaCl} 117, \mathrm{KCl} 3.6, \mathrm{CaCl}_{2}$ 1.2, $\mathrm{NaH}_{2} \mathrm{PO}_{4}$ 1.2, $\mathrm{MgCl}_{2} 1.2$, $\mathrm{NaHCO}_{3} 25$ and glucose 11) bubbled with $95 \% \mathrm{O}_{2}-5 \% \mathrm{CO}_{2}$. Rats were killed by exsanguination. A transverse slice (thickness: $500 \mu \mathrm{m}$ ) was cut using a microslicer (DTK-1000, Dousaka, Kyoto, Japan) in oxygenated icecold Krebs solution. The slice was then transferred to the recording chamber (volume: $1.5 \mathrm{ml}$ ), and continuously perfused with pre-heated $\left(35^{\circ} \mathrm{C} \pm 1^{\circ} \mathrm{C}\right.$; when measured in the chamber) and oxygenated Krebs solution for at least $1 \mathrm{hr}$ before recordings.

\subsection{Whole-Cell Voltage-Clamp Recordings and Focal Stimulation}

The SG can be identified under a stereomicroscope as a translucent band across the spinal dorsal horn [20] [38] [47]. Spinal cord slices could be maintained for up to $12 \mathrm{hr}$ when they were superfused at a rate of $15-20$ $\mathrm{ml} / \mathrm{min}$ with pre-oxygenated Krebs solution at $35^{\circ} \mathrm{C} \pm 1^{\circ} \mathrm{C}$. The conventional blind whole-cell patch-clamp technique was applied to the SG neurons. The recorded neurons were located at the center of SG to avoid recordings from laminae I and III neurons. Patch-pipettes were filled with solution (in mM): $\mathrm{Cs}_{2} \mathrm{SO}_{4} 110, \mathrm{CaCl}_{2} 0.5, \mathrm{MgCl}_{2}$ 2, EGTA 5, HEPES 5, Mg-ATP 5 and tetraethylammonium (TEA)-Cl 5; and had a resistance of $10-15 \mathrm{M} \Omega$. After making a rigid seal (resistance: 5 - $20 \mathrm{G} \Omega$ ) in the cell-attached mode by a gentle suction into the patchpipette, the membrane patch was ruptured by a brief period of more powerful suction, resulting in the whole-cell configuration. Only neurons having resting membrane potentials more negative than $-55 \mathrm{mV}$ in the current-clamp mode were voltage-clamped and then holding potential $\left(\mathrm{V}_{\mathrm{H}}\right)$ was shifted to $0 \mathrm{mV}$ used to record IPSCs, as reported previously [17] [38]. $\mathrm{K}^{+}$-channel blockers $\left(\mathrm{Cs}^{+}\right.$and TEA) were added to the patch-pipette solution to easily perform the shift of $\mathrm{V}_{\mathrm{H}}$ and also to shorten the electrotonic length of the dendrites. The recordings of IPSCs started several minutes after the whole-cell mode. Recordings from single neurons under this condition were stable for up to $1 \mathrm{hr}$.

Electrically-evoked inhibitory postsynaptic currents (IPSCs) were triggered at 0.1 or $0.2 \mathrm{~Hz}$ by stimulating SG neurons (somata and axons) with rectangular pulses (duration: $0.1 \mathrm{~ms}$ ) using an extracellular monopolar silver-wire electrode (50 $\mu \mathrm{m}$ in diameter; isolated except for the tip) located within $150 \mu \mathrm{m}$ of the recorded neurons; the stimulus intensity was monitored with a digitized output isolator. The amplitude of the evoked IPSC (eIPSC) in response to electrical stimulation varied among the stimuli, possibly because of a fluctuation of the number of quanta released from nerve terminals [see [42] for a similar variation in eIPSC amplitudes]. Pairedpulse stimulation with a short-time interval (15 - $50 \mathrm{~ms})$ was also used to obtain eIPSCs. All signals were amplified by an Axopatch 200B amplifier (Axon Instruments, Foster City, CA, USA), digitized at $333 \mathrm{or} 500 \mathrm{kHz}$ with an A/D converter (Digidata 1200A or 1322; Axon Instruments) and stored on a computer using the pCLAMP 6 or 8 data acquisition program (Axon Instruments).

\subsection{Data Analysis}

The signals were analyzed off-line using an Axograph 4.0 (Axon Instruments). In estimating quantitatively the effects of drugs on evoked transmission at a time, many but not more than six of eIPSC amplitudes were averaged if the amplitudes varied to a large extent in response to individual stimuli. Spontaneous IPSCs (sIPSCs) were automatically analyzed with a variable amplitude template and visually examined to find out whether erroneous sIPSC events were detected; if so, the template was changed and the analysis was repeated. This process was repeated until erroneous sIPSC events were not detected. The frequency and amplitude of sIPSC was calculated from sIPSC events measured for at least $1 \mathrm{~min}$. Data were shown as mean \pm S.E.M., and statistical significance was set at $P<0.05$ using a paired Student's $t$-test (unless otherwise mentioned) or a KolmogorovSmirnov test. In all cases $n$ refers to the number of neurons studied.

\subsection{Application of Drugs}

All drugs were applied by switching the perfusion solution to one containing the drug at a known concentration using a three-way tap. The perfusion rate or temperature was not altered during the drug application. Drug-containing solutions reached to the recording chamber within $10 \mathrm{~s}$. Drugs used were ANA, R(+)-WIN-2 mesylate (Research Biochemicals International, Natick, MA, USA); 6-cyano-7-nitroquinoxaline-2,3-dione (CNQX) from 
Tocris Cookson (Bristol, UK); (-)-bicuculline methiodide and strychnine from Sigma (St. Louis, MO, USA); tetrodotoxin (TTX) from Wako (Osaka, Japan); and SR141716A from the NIMH's Chemical Synthesis and Drug Supply Program. All drugs except TTX, bicuculline and strychnine (where distilled water was used as a solvent) were first dissolved in dimethyl sulfoxide (DMSO) at 1000 times the concentration to be used, and then diluted to the desired concentration in Krebs solution immediately before use. DMSO itself at the highest concentration $(0.1 \%)$ used in the present study did not significantly affect glycinergic and GABAergic eIPSC amplitudes [92\% \pm $6 \%(n=3 ; P>0.05)$ and $97 \%, 112 \%$, respectively, of control around 2 min after the superfusion of DMSO for 2 $\min ]$.

\section{Results}

All SG neurons tested exhibited glutamatergic spontaneous excitatory postsynaptic currents (EPSCs) at a $\mathrm{V}_{\mathrm{H}}$ of $-70 \mathrm{mV}$ where no sIPSCs were observed, since the reversal potential for IPSCs was near $-70 \mathrm{mV}$. On the other hand, when the $\mathrm{V}_{\mathrm{H}}$ was shifted to $0 \mathrm{mV}$, sIPSCs could be encountered in all neurons tested, where no spontaneous EPSCs were invisible owing to the reversal potential for EPSCs to be close to $0 \mathrm{mV}$ [38]. Neither the frequency nor the amplitude of sIPSCs was significantly affected following the application of TTX ( $0.5 \mu \mathrm{M}$; data not shown), indicating that the production of the sIPSCs was independent of the spontaneous activities of neurons presynaptic to SG neurons (see [38]).

\subsection{ANA Reduces Both Glycinergic and GABAergic eIPSC Amplitudes}

Glycinergic and GABAergic eIPSCs were, respectively, evoked in the presence of a $\mathrm{GABA}_{\mathrm{A}}$-receptor antagonist bicuculline $(10 \mu \mathrm{M})$ and a glycine-receptor antagonist strychnine $(1 \mu \mathrm{M})$ together with a non-NMDA receptor antagonist CNQX $(10 \mu \mathrm{M})$ which was added to block the activation of glutamatergic interneurons. The glycinergic eIPSCs were shorter in duration by about three-fold than the GABAergic ones, as reported previously [17] [38]. The glycinergic and GABAergic eIPSCs were stable in amplitude for at least 7 min after the beginning of their recordings (Figure $1(\mathrm{~A})$ ).

In $18(78 \%)$ out of 23 neurons examined, ANA $(10 \mu \mathrm{M})$ superfused for 2 min reduced the amplitude of the glycinergic eIPSC, as seen in Figure 1(B). This action persisted for more than 6 min after washout. The magnitude of this reduction was measured around 2 min after washout (when a maximal effect of adenosine on eIPSC amplitudes in SG neurons was observed under the same condition as that in the present study; see [38]), although the time course of a change in eIPSC amplitudes following ANA superfusion varied among neurons tested, probably due to a difference in their position such as depth from the surface of spinal cord slice. The reductive extent was $27 \% \pm 3 \%(n=18 ; P<0.05)$. The remaining five neurons did not exhibit a change $(>5 \%)$ in the amplitude. GABAergic eIPSC amplitudes also were reduced by ANA $(10 \mu \mathrm{M})$ in a similar manner, as seen in Figure 1(C). This action was observed in 17 (71\%) out of 24 neurons tested with the extent of $42 \% \pm 4 \%(n=$ $17 ; P<0.05$ ) around 2 min after washout. In the remaining five neurons, two neurons exhibited a small increase in the amplitude (by $17 \%$ and $8 \%$ around 2 min in the presence of ANA) while three neurons were not affected by ANA. Since some of the neurons tested did not exhibit the inhibitory action of ANA, the effects of ANA at various concentrations on eIPSCs were examined in single neurons. Figures 2(A)-(B) demonstrate, respectively, the effects on glycinergic and GABAergic eIPSCs of ANA which is applied successively at various concentrations ranging from 1 to $10 \mu \mathrm{M}$. The ANA-induced reductions in glycinergic and GABAergic eIPSC amplitudes were seen at a low concentration such as $1 \mu \mathrm{M}$ with extents of $33 \% \pm 7 \%$ and $20 \% \pm 4 \%$ (each $n=3$ ), respectively, around 2 min after washout. Under the reduction by ANA at a concentration of $5 \mu \mathrm{M}$, ANA $(10 \mu \mathrm{M})$ did not exhibit a further decrease in glycinergic or GABAergic eIPSC amplitudes [103\% and 104\%; 92\% $\pm 19 \%(n=3)$, respectively, of that just before the ANA $(10 \mu \mathrm{M})$ application], indicating an occlusion of ANA actions.

\subsection{The eIPSC Amplitude Reductions Produced by ANA Are Mediated by Cannabinoid Receptors}

We first examined whether a cannabinoid-receptor agonist WIN-2 mimicks the depressive action of ANA on evoked inhibitory transmissions. Figures 3(A)-(B) demonstrate the effects of WIN-2 (5 $\mu \mathrm{M})$ superfused for 2 min on evoked glycinergic and GABAergic transmissions, respectively. In 8 (80\%) out of 10 neurons tested, WIN-2 reduced glycinergic eIPSC amplitudes in a manner similar to that of ANA, as seen in Figure 3(A). 
Glycinergic eIPSC

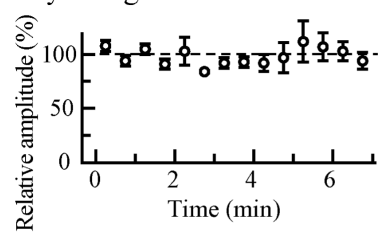

Glycinergic eIPSC

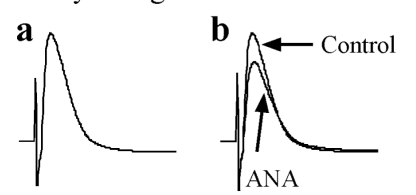

c

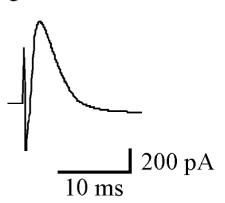

GABAergic eIPSC

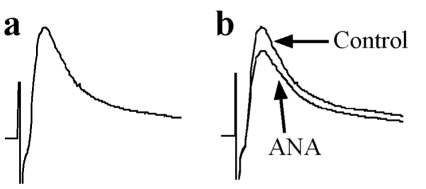

c

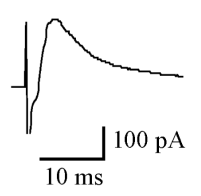

(C)
(B)

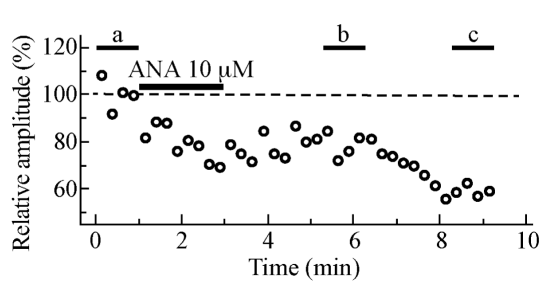

GABAergic eIPSC

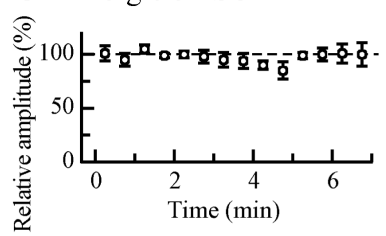

(A)

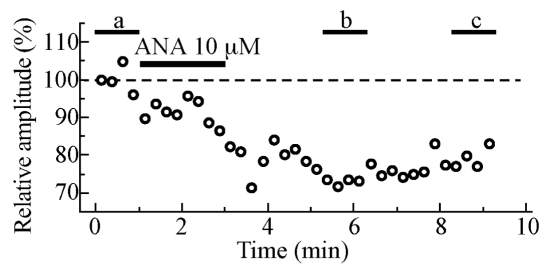

Figure 1. Reductions by anandamide (ANA; $10 \mu \mathrm{M}$ ) of the peak amplitudes of electrically-evoked IPSCs (eIPSCs) recorded from substantia gelatinosa (SG) neurons. (A) Time courses of the peak amplitudes of glycinergic and GABAergic eIPSCs recorded over 7 min under the condition of control. Each point with vertical bars shows the averaged value of the amplitudes of 3 consecutive eIPSCs, and is the mean and S.E.M. of data obtained from 3 - 4 neurons and expressed as a percentage of the mean of all the values for the amplitudes. (B) \& (C) Glycinergic and GABAergic eIPSCs, respectively, in the control and under the action of ANA. Left records: averaged traces of 12 consecutive eIPSCs in the control (a) and under the action of ANA [b (where control eIPSC is superimposed for comparison) and c]. Right graphs: time courses of changes in the peak amplitudes of eIPSC under the action of ANA, relative to control. Each point shows the averaged value of the amplitudes of 3 consecutive eIPSCs. In each of (B) and (C), averaged results in time ranges (a, b, c) in the right graph correspond to traces $(\mathrm{a}, \mathrm{b}, \mathrm{c})$ in the left record, respectively. The glycinergic and GABAergic eIPSCs were observed in the presence of bicuculline $(10 \mu \mathrm{M})$ and strychnine $(1 \mu \mathrm{M})$, respectively, together with CNQX $(10 \mu \mathrm{M})$; holding potential $\left(\mathrm{V}_{\mathrm{H}}\right)=0 \mathrm{mV}$.

Glycinergic eIPSC

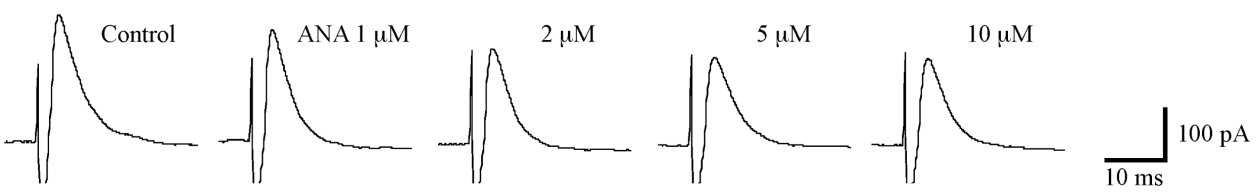

(A)

GABAergic eIPSC

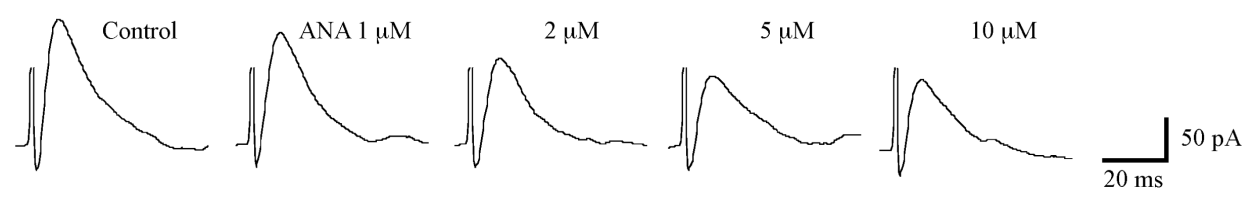

(B)

Figure 2. Effects of ANA at various concentrations on evoked inhibitory transmissions in SG neurons. (A) \& (B) Averaged traces of three consecutive glycinergic and GABAergic eIPSCs, respectively, in the control and under the action of ANA (around 2 min after washout) at concentrations of 1,2, 5 and $10 \mu \mathrm{M}$, where ANA was superfused successively for 2 min at each concentration in the order of low to high ones in the same neuron. Here, there was a time interval of 2 min between the applications of the different concentrations of ANA. The eIPSCs in (A) and (B) were observed in the presence of bicuculline $(10 \mu \mathrm{M})$ and strychnine $(1 \mu \mathrm{M})$, respectively, together with CNQX $(10 \mu \mathrm{M}) ; \mathrm{V}_{\mathrm{H}}=0 \mathrm{mV}$. 


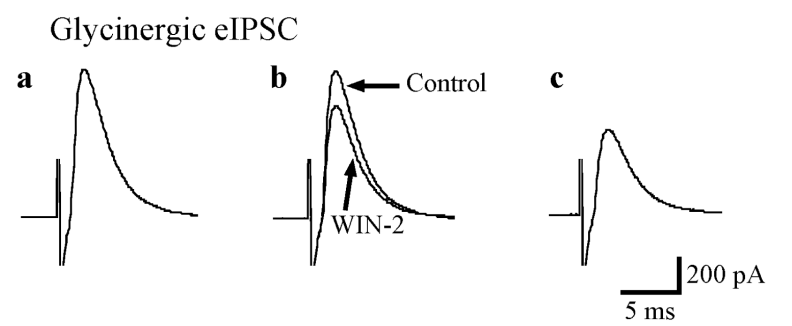

(A)

GABAergic eIPSC

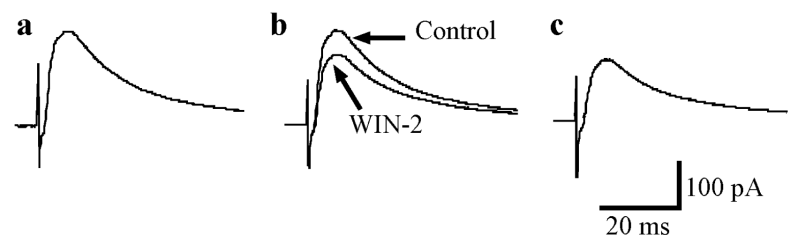

(B)
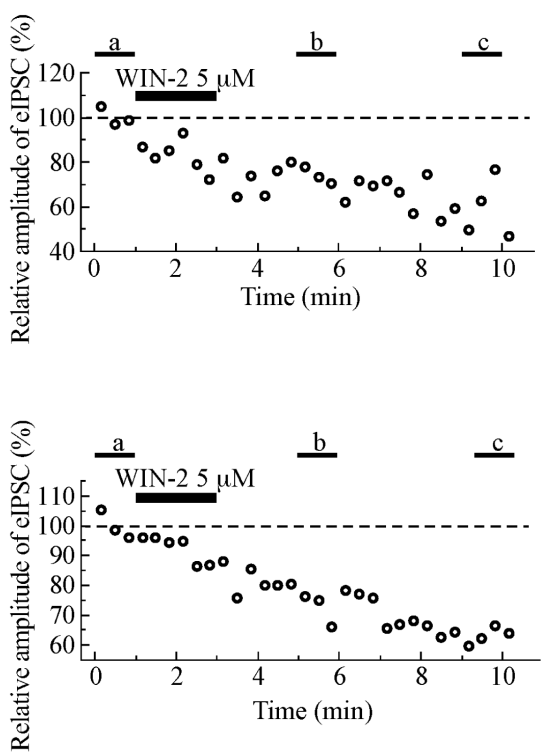

\begin{abstract}
Figure 3. Reductions by WIN55,212-2 (WIN-2; $5 \mu \mathrm{M}$ ) of the peak amplitudes of eIPSCs recorded from SG neurons. (A) \& (B) Glycinergic and GABAergic eIPSCs, respectively, in the control and under the action of WIN-2. Left records: averaged traces of 6 consecutive eIPSCs in the control (a) and under the action of WIN-2 [b (where control eIPSC is superimposed for comparison) and c]. Right graphs: time courses of changes in the peak amplitudes of eIPSC under the action of WIN-2, relative to control. Each point shows the averaged value of the amplitudes of two consecutive eIPSCs. In each of (A) and (B), averaged results in time ranges $(\mathrm{a}, \mathrm{b}, \mathrm{c})$ in the right graph correspond to traces $(\mathrm{a}, \mathrm{b}, \mathrm{c})$ in the left record, respectively. The eIPSCs in (A) and (B) were observed in the presence of bicuculline $(10 \mu \mathrm{M})$ and strychnine $(1 \mu \mathrm{M})$, respectively, together with $\mathrm{CNQX}(10 \mu \mathrm{M}) ; \mathrm{V}_{\mathrm{H}}=0 \mathrm{mV}$.
\end{abstract}

When estimated around 2 min after washout of WIN-2 in a manner similar to that for ANA actions, the magnitude of the reduction was $20 \% \pm 4 \%(n=8 ; P<0.05)$. The remaining two neurons did not exhibit the reduction. GABAergic eIPSC amplitudes also were reduced by WIN-2 $(5 \mu \mathrm{M})$ in a manner similar to that for glycinergic eIPSCs, as seen in Figure 3(B). This action was observed in 13 (68\%) out of 19 neurons tested with the extent of $28 \% \pm 4 \%(n=13 ; P<0.05)$ around 2 min after washout. In the remaining four neurons, two neurons exhibited a small increase in the amplitude (by $25 \%$ and $11 \%$ around $2 \mathrm{~min}$ in the presence of WIN-2) while other two neurons were not affected by WIN-2. An endogenous agonist of cannabinoid receptors, 2-arachydonoyl glycerol (2-AG; $20 \mu \mathrm{M}$; [48]), the level of which is considerably higher than that of ANA in the spinal cord [49], also reduced eIPSC amplitudes, as shown in Figure 4. The magnitudes of the reductions in glycinergic and GABAergic eIPSC amplitudes were, respectively, 32\% $\pm 11 \%(n=4 ; P<0.05)$ and $30 \% \pm 5 \%(n=4 ; P<0.05)$ around 2 min after washout of 2-AG.

We next examined how a CB1-receptor antagonist SR141716A (5 $\mu \mathrm{M})$ affects the reductions in eIPSC amplitudes by ANA $(10 \mu \mathrm{M})$. SR141716A by itself did not significantly affect glycinergic and GABAergic eIPSC amplitudes [90\% $\pm 2 \%(n=6)$ and $93 \% \pm 7 \%(n=5)$ of control, respectively, about 2 min after the commencement of its superfusion], and following its washout there was not a further change in the amplitudes, as different from ANA and WIN-2 actions. Since the inhibitory effect of ANA on eIPSCs was not observed in some of the neurons tested, we examined whether the inhibition persisting after washout of ANA is reduced by SR141716A, as done for the inhibitory effect of WIN-2 on evoked inhibitory transmissions in spinal trigeminal SG neurons [42]. In neurons where ANA $(10 \mu \mathrm{M})$ attenuated glycinergic or GABAergic eIPSC amplitude, the amplitude recovered to the control level by SR141716A (5 $\mathrm{MM})$, as seen in Figure 5. In neurons which exhibited an amplitude reduction of $46 \% \pm 11 \%(n=4 ; P<0.05)$ around 2 min after washout of ANA, glycinergic eIPSC amplitudes recovered to $84 \% \pm 8 \%$ of those before ANA application around 2 min after the beginning of SR141716A superfusion. Following SR141716A superfusion for 2 min, GABAergic eIPSC amplitudes recovered to 109\% and $99 \%$ of those before ANA application which resulted in a reduction in the amplitude (by 57\% and $25 \%$ around 2 min after washout). 
Glycinergic eIPSC
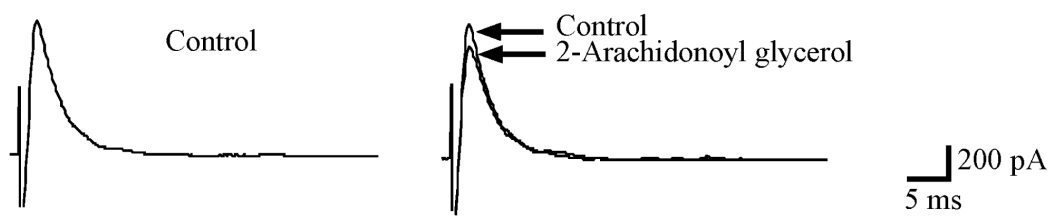

(A)

GABAergic eIPSC
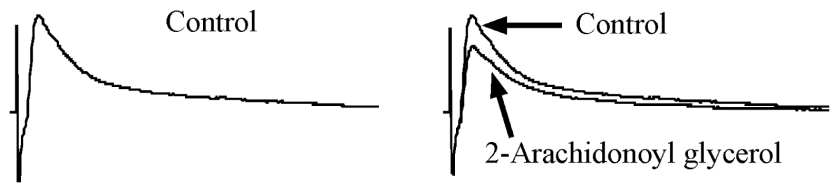

$\underset{10 \mathrm{~ms}}{ل} 100 \mathrm{pA}$

(B)

Figure 4. Reductions by 2-arachidonoyl glycerol $(20 \mu \mathrm{M})$ of the peak amplitudes of eIPSCs recorded from SG neurons. (A) and (B) Averaged traces of 6 consecutive glycinergic and GABAergic eIPSCs, respectively, in the control (left) and under the action of 2-arachidonoyl glycerol (right) where control eIPSC is superimposed for comparison. The eIPSCs in (A) and (B) were observed in the presence of bicuculline $(10 \mu \mathrm{M})$ and strychnine $(1 \mu \mathrm{M})$, respectively, together with CNQX $(10 \mu \mathrm{M}) ; \mathrm{V}_{\mathrm{H}}=0 \mathrm{mV}$.

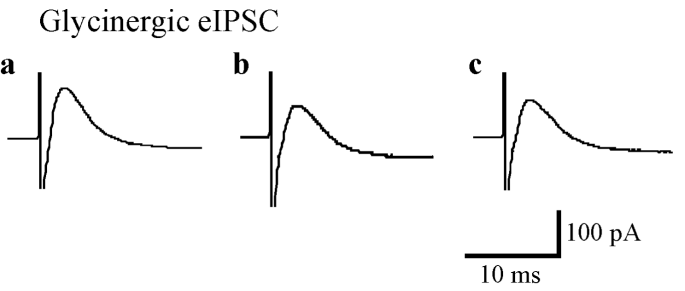

GABAergic eIPSC

a<smiles>CC1CCCCC1C</smiles>

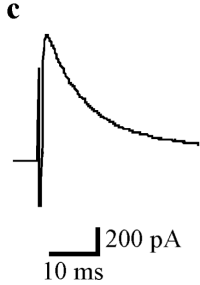

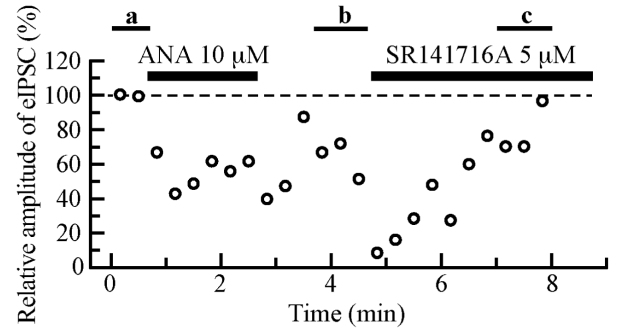

(A)

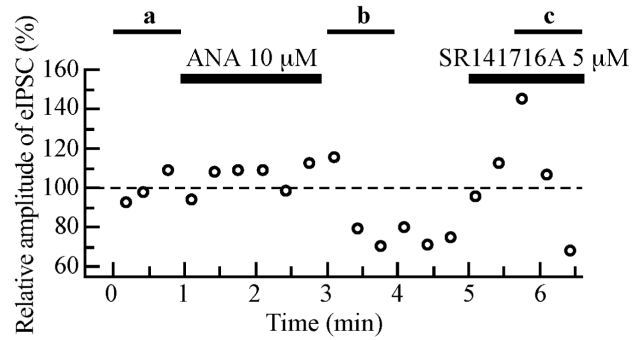

(B)

Figure 5. Reduced eIPSC amplitudes by ANA (10 $\mu \mathrm{M})$ recovered to the control level by SR141716A (5 $\mu \mathrm{M}$ ) in SG neurons. (A) \& (B) Glycinergic and GABAergic eIPSCs, respectively, in the control, under the action of ANA and a recovery from its action in the presence of SR141716A. Left records: averaged traces of 4 - 6 consecutive glycinergic and GABAergic eIPSCs in the control (a), under the action of ANA (b) and following superfusion of SR141716A (c). Right graphs: time courses of changes in the peak amplitudes of eIPSC by applying SR141716A under the inhibitory action of ANA, relative to control. Each point shows the averaged value of the amplitudes of two consecutive eIPSCs. In each of (A) and (B), averaged results in time ranges $(\mathrm{a}, \mathrm{b}, \mathrm{c})$ in the right graph correspond to traces $(\mathrm{a}, \mathrm{b}, \mathrm{c})$ in the left record, respectively. The eIPSCs in (A) and (B) were observed in the presence of bicuculline $(10 \mu \mathrm{M})$ and strychnine $(1 \mu \mathrm{M})$, respectively, together with CNQX $(10 \mu \mathrm{M}) ; \mathrm{V}_{\mathrm{H}}=0 \mathrm{mV}$.

\subsection{ANA Increases Paired-Pulse Ratios of eIPSC Amplitudes}

To characterize the reductions in eIPSC amplitudes by ANA, we carried out a paired-pulse experiment with a 
time interval of 15 - $50 \mathrm{~ms}$, where the interval used for glycinergic eIPSCs was shorter than that for GABAergic eIPSCs because the former eIPSCs were shorter in duration than the latter ones, as described above. Glycinergic and GABAergic eIPSCs exhibited a paired-pulse depression (PPD) or paired-pulse facilitation (PPF) in a manner dependent on the paired-pulse intervals used, as seen in the most left traces of Figure 6, although these phenomena were not examined here in detail. When examined in neurons exhibiting the ANA-induced reductions in eIPSC amplitudes, a ratio of the second to first eIPSC amplitude in each case of PPD and PPF was increased by ANA $(10 \mu \mathrm{M})$. The amplitude ratios in the PPD (0.706) and PPF (1.11; see Figure 6(A)) of glycinergic eIPSC amplitudes were increased by $21 \%$ and $9 \%$, respectively (the first eIPSC amplitude reduction by ANA: $35 \%$ and 16\%, respectively). The amplitude ratios in the PPD (0.959 and 0.895 [see Figure 6(B)]) and PPF (1.18) of GABAergic eIPSC amplitudes were increased by 18\%, 65\% and 22\%, respectively (the first eIPSC amplitude reduction by ANA: $56 \%, 39 \%$ and $14 \%$, respectively).

\subsection{ANA Reduces the Frequency but Not Amplitude of SIPSC}

Two kinds of glycinergic and GABAergic sIPSCs could be encountered in SG neurons, as reported previously [17] [38]. ANA $(10 \mu \mathrm{M})$ superfused for 2 min reduced the frequency of glycinergic sIPSCs which were observed in the presence of bicuculline $(10 \mu \mathrm{M})$. This action persisted several minutes after washout of ANA, as seen in Figure 7(A). Figure 7(A) also demonstrates cumulative distributions of the amplitude and inter-event interval of glycinergic sIPSC in the control and under the action of ANA. A proportion of sIPSCs having a longer inter-event interval was increased by ANA while there was not a change in the cumulative distribution of sIPSC amplitude. In 5 out of 7 neurons examined, when estimated around 1 min after washout of ANA (when its inhibitory action on eIPSCs was apparent; see Figure 1), glycinergic sIPSC frequency was on average reduced by $46 \% \pm 5 \%(n=5 ; P<0.01$; control: $2.09 \pm 0.27 \mathrm{~Hz})$, whereas the amplitude was unchanged [95\% $\pm 3 \%(P>$ $0.05)$ of control $(25.4 \pm 4.7 \mathrm{pA})]$. Remaining two neurons did not respond to ANA. In the presence of strychnine $(1 \mu \mathrm{M})$, GABAergic sIPSCs, which were longer by about three-fold in duration than glycinergic ones (compare sIPSC traces in a fast time scale in Figures 7(A)-(B); see also [38]) as seen for the corresponding eIPSCs, could be recorded. As seen for glycinergic sIPSCs, ANA $(10 \mu \mathrm{M})$ superfused for 2 min reduced GABAergic sIPSC frequency (see Figure 7(B)). When cumulative distributions of the amplitude and inter-event interval of GABAergic sIPSC were examined as shown in Figure 7(B), ANA increased a proportion of sIPSCs having a longer inter-event interval while unaffecting the cumulative distribution of sIPSC amplitude. In all of five neurons tested, when estimated around 1 min after washout of ANA, the GABAergic sIPSC frequency was decreased by $35 \% \pm 7 \%(n=5 ; P<0.05$; control: $1.04 \pm 0.35 \mathrm{~Hz})$ without a change in the amplitude [93\% $\pm 4 \%(P>0.05)$ of control $(19.6 \pm 3.6 \mathrm{pA})]$.

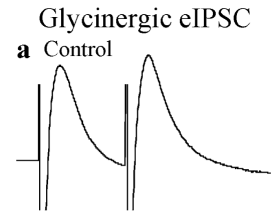

GABAergic eIPSC
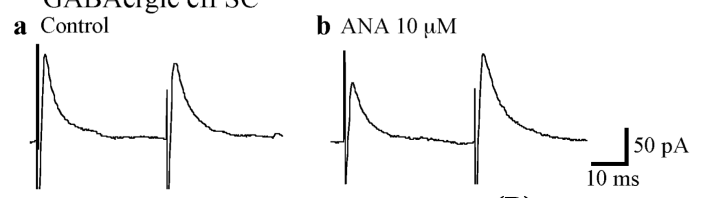

(B)

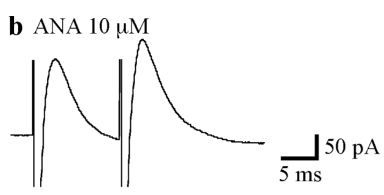

(A)
Figure 6. Effects of ANA (10 $\mu \mathrm{M})$ on evoked glycinergic and GABAergic inhibitory transmissions in response to a paired-pulse stimulus in SG neurons. (A) and (B) Averaged traces of 6 consecutive paired-pulse induced glycinergic and GABAergic eIPSCs, respectively, (with a time interval of 20 and $40 \mathrm{~ms}$, respectively) in the control (a), under the action of ANA (b) and their superimposition (c; where the first eIPSC in the paired eIPSC in the control was scaled to that under the action of ANA).The eIPSCs in $(\mathrm{A})$ and $(\mathrm{B})$ were observed in the presence of bicuculline $(10 \mu \mathrm{M})$ and strychnine $(1$ $\mu \mathrm{M})$, respectively, together with CNQX $(10 \mu \mathrm{M}) ; \mathrm{V}_{\mathrm{H}}=0 \mathrm{mV}$.
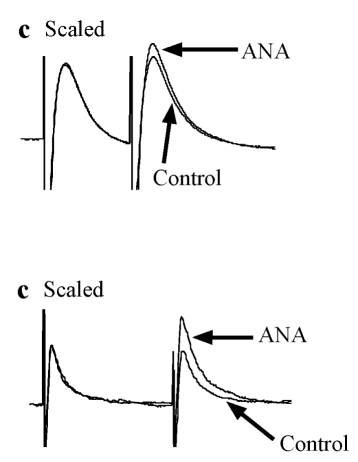

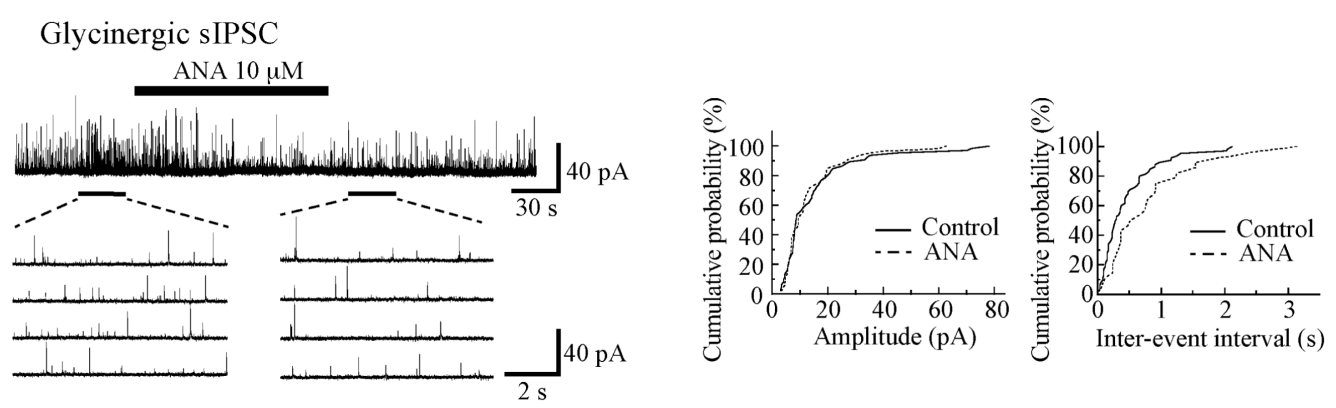

GABAergic sIPSC
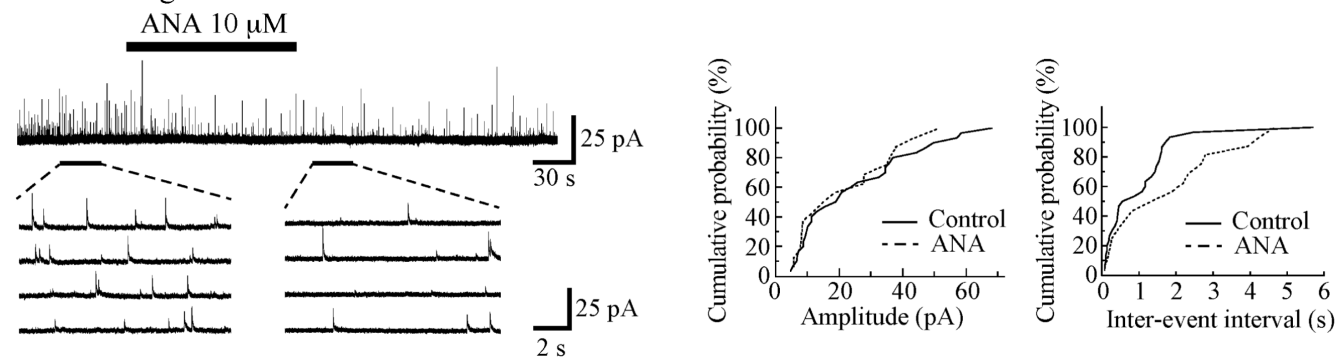

(B)

\begin{abstract}
Figure 7. Effects of ANA $(10 \mu \mathrm{M})$ on glycinergic (A) and GABAergic spontaneous inhibitory transmissions (B) in SG neurons. Continuous chart recordings of glycinergic and GABAergic sIPSCs (upper in (A) and (B)) in the control and under the action of ANA. The horizontal bars above records indicate the period of time during which ANA is applied. Traces given below the chart recordings show sIPSCs, which are shown in an expanded scale in time, recorded consecutively for a period indicated by a bar shown below the recordings. In the right two graphs of (A), are shown cumulative histograms of the amplitude and inter-event interval of glycinergic sIPSC in the control (continuous line) and under the action of ANA (dotted line), where their histograms are made from sIPSCs measured for 1 min (127 and 69 sIPSC events, respectively). ANA had no effect on the amplitude distribution $(P=0.26)$ while shifting the interval distribution to a longer one ( $P<0.05$; Kolmogorov-Smirnov test). In the right two graphs of (B), are shown cumulative histograms of the amplitude and inter-event interval of GABAergic sIPSC in the control (continuous line) and under the action of ANA (dotted line), where their histograms are made from sIPSCs measured for 1 min (51 and 28 sIPSC events, respectively). ANA had no effect on the amplitude distribution $(P=0.37)$ while shifting the interval distribution to a longer one $(P<0.05$; Kolmogorov-Smirnov test). (A) and (B) were obtained in the presence of bicuculline $(10 \mu \mathrm{M})$ and strychnine $(1 \mu \mathrm{M})$, respectively; $\mathrm{V}_{\mathrm{H}}=0 \mathrm{mV}$.
\end{abstract}

\title{
4. Discussion
}

The present study demonstrated that ANA reduces glycinergic and GABAergic eIPSC amplitudes and sIPSC frequencies in many of the adult rat SG neurons examined. These actions were presynaptic in origin, because glycinergic and GABAergic sIPSC amplitudes were not affected by ANA. This idea is supported by pairedpulse experiments, because ANA increases a ratio of the second to first glycinergic or GABAergic eIPSC amplitude. This increase would not be expected if ANA inhibits a sensitivity of postsynaptic neurons to glycine or GABA and as a result the first and second eIPSC amplitudes are reduced by the same extent.

\subsection{Depression of Inhibitory Transmission by ANA Is Mediated by CB1 Receptors}

The reductions in glycinergic and GABAergic eIPSC amplitudes by ANA were mimicked by the CB1/CB2 receptor agonist WIN-2 and disappeared in the presence of the selective CB1 receptor antagonist SR141716A, indicating an involvement of CB1 receptors. This action of WIN-2 as well as ANA persisted at least 7 min after washout, as seen in the inhibitory action of WIN-2 on GABAergic eIPSCs in the hippocampus [40]. This persistence would be possibly due to a lipophilic nature of the cannabinoids. A similar inhibition by WIN-2 of glycinergic and GABAergic inhibitory transmissions has been reported in superficial dorsal horn neurons in young mice [44]. 
Since it is known that ANA activates not only CB1 receptors but also transient receptor potential (TRP) vanilloid-1 (TRPV1) channels [50] and that SR141716A inhibits TRPV1 responses [51], the ANA-induced inhibition may have been mediated by both CB1 receptors and TRPV1 channels. This is, however, unlikely in the case of ANA $(10 \mu \mathrm{M})$ actions in the SG, because ANA at a high concentration such as $20 \mu \mathrm{M}$ enhances glutamatergic spontaneous transmission in a manner sensitive to a non-selective TRP antagonist ruthenium red [52] while ANA at $10 \mu \mathrm{M}$ does not affect the transmission [24]. TRPV1 channels in the spinal trigeminal SG are activated by ANA at a higher concentration such as $30 \mu \mathrm{M}$ [53]. Furthermore, a TRPV1 agonist capsaicin has no effect on glycinergic and GABAergic eIPSCs (and also sIPSCs) in SG neurons ([54] [55]; for review see [56]).

Although 2-AG is known to be more potent than ANA in activating CB1 receptors [57], this fact does not appear to be applied to their depressive effects on inhibitory transmissions in the present study, because the IPSC amplitude reduction produced by $2-\mathrm{AG}(20 \mu \mathrm{M})$ is comparable in extent to that of ANA (10 $\mu \mathrm{M})$. This may be due to the fact that 2-AG is more easily degraded than ANA by their inactivating enzymes such as ANA amidohydrolase (for review see [58]) in spinal cord slices.

The presynaptic effect of ANA on GABAergic transmission is consistent with the presence of GABA in CB1 receptor-like immunoreactive SG neurons [11]. The fact that the ANA action was seen in some of the SG neurons examined may be consistent with the observation that a part of CB1 receptor-like immunoreactive SG neurons was labeled for GABA [11] or that GABAergic neuron terminals in the SG originate from not only SG interneurons but also other laminae and medullary neurons (for review see [59]). Even if the descending pathways from the medulla have been disrupted in the slice preparation used in the present study, it is not unlikely that nerve terminals originating from the pathways are intact and thus exhibit the spontaneous and evoked releases of glycine and/or GABA, considering that single neurons isolated using an enzyme-free and mechanical dissociation procedure have adherent functional synaptic terminals (for review see [60]). Since some of SG inhibitory neuron terminals appeared to express CB1 receptors, neurons not responding to cannabinoids were excluded from the statistical analysis of the reductions in eIPSC amplitude and sIPSC frequency by cannabinoids.

Presynaptic inhibition of GABAergic transmission by CB1 receptor activation similar to that in the spinal cord SG has been reported in the corpus striatum [39], the hippocampal CA1 [40] [41], the spinal trigeminal SG [42] and the SNR [43]. Jennings et al. [42] have demonstrated CB1 receptor-mediated presynaptic inhibition of glycinergic transmission in the spinal trigeminal SG. Although the superfusion time (2 min) of cannabinoids used in the present study was shorter than those (10 - $20 \mathrm{~min})$ in previous studies and thus the result obtained may not have been in a steady state, the GABAergic eIPSC amplitude reduction produced by WIN-2 was almost similar in extent among different types of neurons [spinal cord SG: $28 \%$ at $5 \mu \mathrm{M}$ (present study); hippocampal CA1: $47 \%$ at $5 \mu \mathrm{M}$ ([40]); spinal trigeminal SG: $35 \%$ at $3 \mu \mathrm{M}$ ([42]); SNR: $43 \%$ at $10 \mu \mathrm{M}$ ([43])]. This may be due to the fact that the superfusion rate $(15-20 \mathrm{ml} / \mathrm{min})$ used in our study is much larger than those $(1-2$ $\mathrm{ml} / \mathrm{min}$ ) in other studies.

Although a cellular mechanism for the ANA action is not examined here, this would be due to an inhibition of voltage-gated $\mathrm{Ca}^{2+}$ channels present in nerve terminals, because WIN-2 inhibits $\mathrm{Ca}^{2+}$-channel currents in AtT20 cells transfected with CB1 receptors [61] and in cultured rat hippocampal neurons [62]. Liang et al. [25] have demonstrated a presynaptic inhibition by WIN-2 of glutamatergic transmission in a manner sensitive to N-type $\mathrm{Ca}^{2+}$-channel blockers. This idea about the involvement of $\mathrm{Ca}^{2+}$ channels could be applied to the reductions in not only eIPSC amplitude but also sIPSC frequency, because sIPSC frequency in SG neurons is decreased in $\mathrm{Ca}^{2+}$-free Krebs solution and thus presynaptic $\mathrm{Ca}^{2+}$ channels are partially open at the resting state, resulting in a tonic $\mathrm{Ca}^{2+}$ entry in nerve terminals [38].

It is of interest to note that there is a similarity in cannabinoids-induced inhibition between glycinergic and GABAergic transmissions. This result might be due to the fact that these two kinds of synapses are controlled under a similar release machinery. Spinal dorsal horn, especially SG, neurons contain both glycine and GABA, which might be co-released into the dorsal horn [26]. Similar inhibitions by WIN-2 between glycinergic and GABAergic transmissions have been reported in the rodent spinal cord and trigeminal SG [42] [44]. No difference in presynaptic modulation between glycinergic and GABAergic transmissions is also seen in the action of adenosine in the rat spinal cord SG [38]. On the other hand, the glycinergic and GABAergic transmissions in the SG neurons are affected by a phospholipase $A_{2}$ activator melittin in a manner different from each other [34] [63]. Thus, it seems to be unlikely that the glycinergic and GABAergic transmissions in SG neurons are always modulated in a similar manner. 


\subsection{Physiological Significance of the Depressive Effects of Cannabinoids on Inhibitory Transmissions in SG Neurons}

The depressive effects of cannabinoids on inhibitory transmissions are expected to lead to an increase in the excitability of SG neurons, a result different from those of other endogenous analgesics in such that the inhibitory transmissions are facilitated by noradrenaline [31], acetylcholine ([32]-[34]), serotonin ([35]) and oxytocin ([36] [37]) and is not affected by opioids ([17]), nociceptin ([19]) and galanin ([22]) in adult rat SG neurons. On the other hand, adenosine exhibits a disinhibitory effect similar to that of cannabinoids. A part of antinociception produced by intrathecally-administered cannabinoids has been reported to be due to the release of endogenous analgesics such as noradrenaline [5] and opioids ([64]; for review see [1]). The cannabinoid-induced disinhibition may result in the release of the endogenous analgesics which inhibit excitatory transmission in SG neurons. Alternatively, the presynaptic depression of inhibitory transmission as revealed in the present study may lead to the reduction in background noise as a result of a decrease in opening of glycine and $\mathrm{GABA}_{\mathrm{A}}$ receptor-channels which in turn could increase input resistance and thus make SG neurons electrically compact, contributing to the modulation of nociceptive transmission, as suggested for the disinhibitory action of adenosine [38]. As different from the above-mentioned idea that the depressions of inhibitory transmissions by cannabinoids are involved in antinociception, Pernía-Andrade et al. [44] have proposed the idea that such depressions mediate primary-afferent C-fiber induced pain sensitization.

The spinal cord contains a high level of ANA and 2-AG ([45] [49]). Wallmichrath and Szabo [43] have reported a continuous inhibition of GABAergic transmission by endocannabinoids in the SNR. Therefore, inhibitory transmissions in SG neurons may have been tonically depressed by the endocannabinoids. However, this is not the case in the present study, because SR141716A alone does not affect glycinergic and GABAergic eIPSC amplitudes in SG neurons.

With respect to the origin of endocannabinoids, ANA and 2-AG appear to be released from neurons as a result of an increase in neuronal activities including the activation of voltage-gated $\mathrm{Ca}^{2+}$ channels and of metabotropic glutamate receptors, probably through a hydrolysis of phospholipid precursors from membrane phosphoglycerides. The endocannabinoids may mediate signals from postsynaptic neurons to presynaptic terminals in a retrograde manner, resulting in the reduction in the release of glycine and/or GABA, as shown in the hippocampus ([41]; for review see [65] [66]). It remains to be examined what kinds of neuronal activity induce the endocannabinoid-mediated modulation of inhibitory transmission in the SG. Since Hashimotodani et al. [67] have demonstrated that neuronal proteinase-activated receptor 1 (PAR-1) drives synaptic retrograde signaling of an eIPSC inhibition mediated by 2-AG in cultured rat hippocampal neurons, PAR-1 activation in postsynaptic neurons may be one candidate for retrograde one in the SG. It remains to be examined how PAR-1 activation affects inhibitory transmissions in SG neurons, although this activation facilitates glutamatergic spontaneous excitatory transmission in SG neurons [47].

\section{Conclusion}

The present study demonstrated that ANA depressed glycinergic and GABAeregic transmissions in adult rat SG neurons by activating CB1 receptors in nerve terminals. This depression could contribute to the modulation of nociceptive transmission by ANA together with its inhibitory action on excitatory transmission as reported previously [23] [24].

\section{Acknowledgements}

This work was supported by Grants-in-aid for Scientific Research from the Ministry of Education, Science, Sports and Culture of Japan (KAKENHI: 14580790).

\section{References}

[1] Pertwee, R.G. (2001) Cannabinoid Receptors and Pain. Progress in Neurobiology, 63, 569-611. http://dx.doi.org/10.1016/S0301-0082(00)00031-9

[2] Freund, T.F., Katona, I. and Piomelli, D. (2003) Role of Endogenous Cannabinoids in Synaptic Signaling. Physiological Reviews, 83, 1017-1066. http://dx.doi.org/10.1152/physrev.00004.2003

[3] Walker, J.M. and Hohmann, A.G. (2005) Cannabinoid Mechanisms of Pain Suppression. Handbook of Experimental 
Pharmacology, 168, 509-554. http://dx.doi.org/10.1007/3-540-26573-2_17

[4] Manzanares, J., Julian, M.D. and Carrascosa, A. (2006) Role of the Cannabinoid System in Pain Control and Therapeutic Implications for the Management of Acute and Chronic Pain Episodes. Current Neuropharmacology, 4, 239257. http://dx.doi.org/10.2174/157015906778019527

[5] Lichtman, A.H. and Martin, B.R. (1991) Cannabinoid-Induced Antinociception Is Mediated by a Spinal $\alpha_{2}$-Noradrenergic Mechanism. Brain Research, 559, 309-314. http://dx.doi.org/10.1016/0006-8993(91)90017-P

[6] Hohmann, A.G., Tsou, K. and Walker, J.M. (1998) Cannabinoid Modulation of Wide Dynamic Range Neurons in the Lumbar Dorsal Horn of the Rat by Spinally Administered WIN55,212-2. Neuroscience Letters, 257, 119-122. http://dx.doi.org/10.1016/S0304-3940(98)00802-7

[7] Mailleux, P. and Vanderhaeghen, J.-J. (1992) Distribution of Neuronal Cannabinoid Receptor in the Adult Rat Brain: A Comparative Receptor Binding Radioautography and in Situ Hybridization Histochemistry. Neuroscience, 48, 655668. http://dx.doi.org/10.1016/0306-4522(92)90409-U

[8] Hohmann, A.G., Briley, E.M. and Herkenham, M. (1999) Pre- and Postsynaptic Distribution of Cannabinoid and Mu Opioid Receptors in Rat Spinal Cord. Brain Research, 822, 17-25. http://dx.doi.org/10.1016/S0006-8993(98)01321-3

[9] Tsou, K., Brown, S., Sañudo-Peña, M.C., Mackie, K. and Walker, J.M. (1998) Immunohistochemical Distribution of Cannabinoid CB1 Receptors in the Rat Central Nervous System. Neuroscience, 83, 393-411. http://dx.doi.org/10.1016/S0306-4522(97)00436-3

[10] Farquhar-Smith, W.P., Egertová, M., Bradbury, E.J., McMahon, S.B., Rice, A.S.C. and Elphick, M.R. (2000) Cannabinoid $\mathrm{CB}_{1}$ Receptor Expression in Rat Spinal Cord. Molecular and Cellular Neuroscience, 15, 510-521. http://dx.doi.org/10.1006/mcne.2000.0844

[11] Salio, C., Fischer, J., Franzoni, M.F. and Conrath, M. (2002) Pre- and Postsynaptic Localizations of the CB1 Cannabinoid Receptor in the Dorsal Horn of the Rat Spinal Cord. Neuroscience, 110, 755-764. http://dx.doi.org/10.1016/S0306-4522(01)00584-X

[12] Hegyi, Z., Kis, G., Holló, K., Ledent, C. and Antal, M. (2009) Neuronal and Glial Localization of the Cannabinoid-1 Receptor in the Superficial Spinal Dorsal Horn of the Rodent Spinal Cord. European Journal of Neuroscience, 30, 251262. http://dx.doi.org/10.1111/j.1460-9568.2009.06816.x

[13] Chapman, V. (1999) The Cannabinoid CB $_{1}$ Receptor Antagonist, SR141716A, Selectively Facilitates Nociceptive Responses of Dorsal Horn Neurones in the Rat. British Journal of Pharmacology, 127, 1765-1767. http://dx.doi.org/10.1038/sj.bjp.0702758

[14] Willis Jr., W.D. and Coggeshall, R.E. (1991) Sensory Mechanisms of the Spinal Cord. 2nd Edition, Plenum Press, New York. http://dx.doi.org/10.1007/978-1-4899-0597-0

[15] Fürst, S. (1999) Transmitters Involved in Antinociception in the Spinal Cord. Brain Research Bulletin, 48, $129-141$. http://dx.doi.org/10.1016/S0361-9230(98)00159-2

[16] Todd, A.J. (2010) Neuronal Circuitry for Pain Processing in the Dorsal Horn. Nature Reviews Neuroscience, 11, 823836. http://dx.doi.org/10.1038/nrn2947

[17] Kohno, T., Kumamoto, E., Higashi, H., Shimoji, K. and Yoshimura, M. (1999) Actions of Opioids on Excitatory and Inhibitory Transmission in Substantia Gelatinosa of Adult Rat Spinal Cord. Journal of Physiology (London), 518, 803813. http://dx.doi.org/10.1111/j.1469-7793.1999.0803p.x

[18] Ito, A., Kumamoto, E., Takeda, M., Takeda, M., Shibata, K., Sagai, H. and Yoshimura, M. (2000) Mechanisms for Ovariectomy-Induced Hyperalgesia and Its Relief by Calcitonin: Participation of 5-HT $1 \mathrm{~A}$-Like Receptor on C-Afferent Terminals in Substantia Gelatinosa of the Rat Spinal Cord. Journal of Neuroscience, 20, 6302-6308.

[19] Luo, C., Kumamoto, E., Furue, H., Chen, J. and Yoshimura, M. (2002) Nociceptin Inhibits Excitatory but Not Inhibitory Transmission to Substantia Gelatinosa Neurones of Adult Rat Spinal Cord. Neuroscience, 109, 349-358. http://dx.doi.org/10.1016/S0306-4522(01)00459-6

[20] Kawasaki, Y., Kumamoto, E., Furue, H. and Yoshimura, M. (2003) $\alpha_{2}$ Adrenoceptor-Mediated Presynaptic Inhibition of Primary Afferent Glutamatergic Transmission in Rat Substantia Gelatinosa Neurons. Anesthesiology, 98, 682-689. http://dx.doi.org/10.1097/00000542-200303000-00016

[21] Lao, L.J., Kawasaki, Y., Yang, K., Fujita, T. and Kumamoto, E. (2004) Modulation by Adenosine of A $\delta$ and C PrimaryAfferent Glutamatergic Transmission in Adult Rat Substantia Gelatinosa Neurons. Neuroscience, 125, 221-231. http://dx.doi.org/10.1016/j.neuroscience.2004.01.029

[22] Yue, H.Y., Fujita, T. and Kumamoto, E. (2011) Biphasic Modulation by Galanin of Excitatory Synaptic Transmission in Substantia Gelatinosa Neurons of Adult Rat Spinal Cord Slices. Journal of Neurophysiology, 105, 2337-2349. http://dx.doi.org/10.1152/jn.00991.2010

[23] Morisset, V. and Urban, L. (2001) Cannabinoid-Induced Presynaptic Inhibition of Glutamatergic EPSCs in Substantia 
Gelatinosa Neurons of the Rat Spinal Cord. Journal of Neurophysiology, 86, 40-48.

[24] Luo, C., Kumamoto, E., Furue, H., Chen, J. and Yoshimura, M. (2002) Anandamide Inhibits Excitatory Transmission to Rat Substantia Gelatinosa Neurones in a Manner Different from that of Capsaicin. Neuroscience Letters, 321, 17-20. http://dx.doi.org/10.1016/S0304-3940(01)02471-5

[25] Liang, Y.C., Huang, C.C., Hsu, K.S. and Takahashi, T. (2004) Cannabinoid-Induced Presynaptic Inhibition at the Primary Afferent Trigeminal Synapse of Juvenile Rat Brainstem Slices. Journal of Physiology (London), 555, 85-96. http://dx.doi.org/10.1113/jphysiol.2003.056986

[26] Todd, A.J., Watt, C., Spike, R.C. and Sieghart, W. (1996) Colocalization of GABA, Glycine, and Their Receptors at Synapses in the Rat Spinal Cord. Journal of Neuroscience, 16, 974-982.

[27] Sandkühler, J. (2009) Models and Mechanisms of Hyperalgesia and Allodynia. Physiological Reviews, 89, 707-758. http://dx.doi.org/10.1152/physrev.00025.2008

[28] Zeilhofer, H.U., Wildner, H. and Yévenes, G.E. (2012) Fast Synaptic Inhibition in Spinal Sensory Processing and Pain Control. Physiological Reviews, 92, 193-235. http://dx.doi.org/10.1152/physrev.00043.2010

[29] Moore, K.A., Kohno, T., Karchewski, L.A., Scholz, J., Baba, H. and Woolf, C.J. (2002) Partial Peripheral Nerve Injury Promotes a Selective Loss of GABAergic Inhibition in the Superficial Dorsal Horn of the Spinal Cord. Journal of Neuroscience, 22, 6724-6731.

[30] Coull, J.A.M., Boudreau, D., Bachand, K., Prescott, S.A., Nault, F., Sik, A., de Koninck, P. and de Koninck, Y. (2003) Trans-Synaptic Shift in Anion Gradient in Spinal Lamina I Neurons as a Mechanism of Neuropathic Pain. Nature, 424, 938-942. http://dx.doi.org/10.1038/nature01868

[31] Baba, H., Shimoji, K. and Yoshimura, M. (2000) Norepinephrine Facilitates Inhibitory Transmission in Substantia Gelatinosa of Adult Rat Spinal Cord (Part 1): Effects on Axon Terminals of GABAergic and Glycinergic Neurons. Anesthesiology, 92, 473-484. http://dx.doi.org/10.1097/00000542-200002000-00030

[32] Baba, H., Kohno, T., Okamoto, M., Goldstein, P.A., Shimoji, K. and Yoshimura, M. (1998) Muscarinic Facilitation of GABA Release in Substantia Gelatinosa of the Rat Spinal Dorsal Horn. Journal of Physiology (London), 508, 83-93. http://dx.doi.org/10.1111/j.1469-7793.1998.083br.x

[33] Takeda, D., Nakatsuka, T., Papke, R. and Gu, J.G. (2003) Modulation of Inhibitory Synaptic Activity by a Non- $\alpha 4 \beta 2$, Non- $\alpha 7$ Subtype of Nicotinic Receptors in the Substantia Gelatinosa of Adult Rat Spinal Cord. Pain, 101, 13-23. http://dx.doi.org/10.1016/S0304-3959(02)00074-X

[34] Liu, T., Fujita, T. and Kumamoto, E. (2011) Acetylcholine and Norepinephrine Mediate GABAergic but Not Glycinergic Transmission Enhancement by Melittin in Adult Rat Substantia Gelatinosa Neurons. Journal of Neurophysiology, 106, 233-246. http://dx.doi.org/10.1152/jn.00838.2010

[35] Fukushima, T., Ohtsubo, T., Tsuda, M., Yanagawa, Y. and Hori, Y. (2009) Facilitatory Actions of Serotonin Type 3 Receptors on GABAergic Inhibitory Synaptic Transmission in the Spinal Superficial Dorsal Horn. Journal of Neurophysiology, 102, 1459-1471. http://dx.doi.org/10.1152/jn.91160.2008

[36] Breton, J.D., Veinante, P., Uhl-Bronner, S., Vergnano, A.M., Freund-Mercier, M.J., Schlichter, R. and Poisbeau, P. (2008) Oxytocin-Induced Antinociception in the Spinal Cord Is Mediated by a Subpopulation of Glutamatergic Neurons in Lamina I-II Which Amplify GABAergic Inhibition. Molecular Pain, 4, 19. http://dx.doi.org/10.1186/1744-8069-4-19

[37] Jiang, C.Y., Fujita, T. and Kumamoto, E. (2014) Synaptic Modulation and Inward Current Produced by Oxytocin in Substantia Gelatinosa Neurons of Adult Rat Spinal Cord Slices. Journal of Neurophysiology, 111, 991-1007. http://dx.doi.org/10.1152/jn.00609.2013

[38] Yang, K., Fujita, T. and Kumamoto, E. (2004) Adenosine Inhibits GABAergic and Glycinergic Transmission in Adult Rat Substantia Gelatinosa Neurons. Journal of Neurophysiology, 92, 2867-2877. http://dx.doi.org/10.1152/jn.00291.2004

[39] Szabo, B., Dörner, L., Pfreundtner, C., Nörenberg, W. and Starke, K. (1998) Inhibition of GABAergic Inhibitory Postsynaptic Currents by Cannabinoids in Rat Corpus Striatum. Neuroscience, 85, 395-403. http://dx.doi.org/10.1016/S0306-4522(97)00597-6

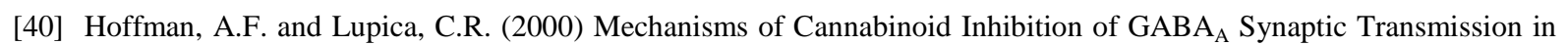
the Hippocampus. Journal of Neuroscience, 20, 2470-2479.

[41] Wilson, R.I. and Nicoll, R.A. (2001) Endogenous Cannabinoids Mediate Retrograde Signalling at Hippocampal Synapses. Nature, 410, 588-592. http://dx.doi.org/10.1038/35069076

[42] Jennings, E.A., Vaughan, C.W. and Christie, M.J. (2001) Cannabinoid Actions on Rat Superficial Medullary Dorsal Horn Neurons in Vitro. Journal of Physiology (London), 534, 805-812.

http://dx.doi.org/10.1111/j.1469-7793.2001.00805.x 
[43] Wallmichrath, I. and Szabo, B. (2002) Analysis of the Effect of Cannabinoids on GABAergic Neurotransmission in the Substantia Nigra Pars Reticulata. Naunyn-Schmiedeberg's Archives of Pharmacology, 365, 326-334. http://dx.doi.org/10.1007/s00210-001-0520-z

[44] Pernía-Andrade, A.J., Kato, A., Witschi, R., Nyilas, R., Katona, I., Freund, T.F., Watanabe, M., Filitz, J., Koppert, W., Schüttler, J., Ji, G., Neugebauer, V., Marsicano, G., Lutz, B., Vanegas, H. and Zeilhofer, H.U. (2009) Spinal Endocannabinoids and $\mathrm{CB}_{1}$ Receptors Mediate C-Fiber-Induced Heterosynaptic Pain Sensitization. Science, 325, 760-764. http://dx.doi.org/10.1126/science.1171870

[45] Yang, H.Y.T., Karoum, F., Felder, C., Badger, H., Wang, T.C.L. and Markey, S.P. (1999) GC/MS Analysis of Anandamide and Quantification of $N$-Arachidonoylphosphatidylethanolamides in Various Brain Regions, Spinal Cord, Testis, and Spleen of the Rat. Journal of Neurochemistry, 72, 1959-1968. http://dx.doi.org/10.1046/j.1471-4159.1999.0721959.x

[46] Kawasaki, Y., Yang, K., Lao, L.J., Matsumoto, N., Fujita, T., Kumamoto, E. and Hasuo, H. (2002) Action of Anandamide on Inhibitory Transmission to Substantia Gelatinosa Neurons in the Rat Spinal Cord. Society for Neuroscience Abstract, 453.4 .

[47] Fujita, T., Liu, T., Nakatsuka, T. and Kumamoto, E. (2009) Proteinase-Activated Receptor-1 Activation Presynaptically Enhances Spontaneous Glutamatergic Excitatory Transmission in Adult Rat Substantia Gelatinosa Neurons. Journal of Neurophysiology, 102, 312-319. http://dx.doi.org/10.1152/jn.91117.2008

[48] Sugiura, T., Kondo, S., Sukagawa, A., Nakane, S., Shinoda, A., Itoh, K., Yamashita, A. and Waku, K. (1995) 2-Arachidonoylglycerol: A Possible Endogenous Cannabinoid Receptor Ligand in Brain. Biochemical and Biophysical Research Communications, 215, 89-97. http://dx.doi.org/10.1006/bbrc.1995.2437

[49] Di Marzo, V., Breivogel, C.S., Tao, Q., Bridgen, D.T., Razdan, R.K., Zimmer, A.M., Zimmer, A. and Martin, B.R. (2000) Levels, Metabolism, and Pharmacological Activity of Anandamide in $\mathrm{CB}_{1}$ Cannabinoid Receptor Knockout Mice: Evidence for Non- $\mathrm{CB}_{1}$, Non- $\mathrm{CB}_{2}$ Receptor-Mediated Actions of Anandamide in Mouse Brain. Journal of Neurochemistry, 75, 2434-2444. http://dx.doi.org/10.1046/j.1471-4159.2000.0752434.X

[50] Zygmunt, P.M., Petersson, J., Andersson, D.A., Chuang, H.H., Sørgård, M., Di Marzo, V., Julius, D. and Högestätt, E.D. (1999) Vanilloid Receptors on Sensory Nerves Mediate the Vasodilator Action of Anandamide. Nature, 400, 452-457. http://dx.doi.org/10.1038/22761

[51] De Petrocellis, L., Bisogno, T., Maccarrone, M., Davis, J.B., Finazzi-Agrò, A. and Di Marzo, V. (2001) The Activity of Anandamide at Vanilloid VR1 Receptors Requires Facilitated Transport across the Cell Membrane and Is Limited by Intracellular Metabolism. Journal of Biological Chemistry, 276, 12856-12863. http://dx.doi.org/10.1074/jbc.M008555200

[52] Morisset, V., Ahluwalia, J., Nagy, I. and Urban, L. (2001) Possible Mechanisms of Cannabinoid-Induced Antinociception in the Spinal Cord. European Journal of Pharmacology, 429, 93-100. http://dx.doi.org/10.1016/S0014-2999(01)01309-7

[53] Jennings, E.A., Vaughan, C.W., Roberts, L.A. and Christie, M.J. (2003) The Actions of Anandamide on Rat Superficial Medullary Dorsal Horn Neurons in Vitro. Journal of Physiology (London), 548, 121-129. http://dx.doi.org/10.1113/jphysiol.2002.035063

[54] Yang, K., Kumamoto, E., Furue, H. and Yoshimura, M. (1998) Capsaicin Facilitates Excitatory but Not Inhibitory Synaptic Transmission in Substantia Gelatinosa of the Rat Spinal Cord. Neuroscience Letters, 255, 135-138. http://dx.doi.org/10.1016/S0304-3940(98)00730-7

[55] Yang, K., Kumamoto, E., Furue, H., Li, Y.Q. and Yoshimura, M. (1999) Action of Capsaicin on Dorsal Root-Evoked Synaptic Transmission to Substantia Gelatinosa Neurons in Adult Rat Spinal Cord Slices. Brain Research, 830, 268273. http://dx.doi.org/10.1016/S0006-8993(99)01408-0

[56] Kumamoto, E., Fujita, T. and Jiang, C.Y. (2014) TRP Channels Involved in Spontaneous L-Glutamate Release Enhancement in the Adult Rat Spinal Substantia Gelatinosa. Cells, 3, 331-362. http://dx.doi.org/10.3390/cells3020331

[57] Savinainen, J.R., Järvinen, T., Laine, K. and Laitinen, J.T. (2001) Despite Substantial Degradation, 2-Arachidonoylglycerol Is a Potent Full Efficacy Agonist Mediating $\mathrm{CB}_{1}$ Receptor-Dependent G-Protein Activation in Rat Cerebellar Membranes. British Journal of Pharmacology, 134, 664-672. http://dx.doi.org/10.1038/sj.bjp.0704297

[58] Ueda, N., Goparaju, S.K., Katayama, K., Kurahashi, Y., Suzuki, H. and Yamamoto, S. (1998) A Hydrolase Enzyme Inactivating Endogenous Ligands for Cannabinoid Receptors. Journal of Medical Investigation, 45, 27-36.

[59] Todd, A.J. and Spike, R.C. (1993) The Localization of Classical Transmitters and Neuropeptides within Neurons in Laminae I-III of the Mammalian Spinal Dorsal Horn. Progress in Neurobiology, 41, 609-645. http://dx.doi.org/10.1016/0301-0082(93)90045-T

[60] Akaike, N. and Moorhouse, A.J. (2003) Techniques: Applications of the Nerve-Bouton Preparation in Neuropharmacology. Trends in Pharmacological Sciences, 24, 44-47. http://dx.doi.org/10.1016/S0165-6147(02)00010-X 
[61] Mackie, K., Lai, Y., Westenbroek, R. and Mitchell, R. (1995) Cannabinoids Activate an Inwardly Rectifying Potassium Conductance and Inhibit Q-Type Calcium Currents in AtT20 Cells Transfected with Rat Brain Cannabinoid Receptor. Journal of Neuroscience, 15, 6552-6561.

[62] Twitchell, W., Brown, S. and Mackie, K. (1997) Cannabinoids Inhibit N- and P/Q-Type Calcium Channels in Cultured Rat Hippocampal Neurons. Journal of Neurophysiology, 78, 43-50.

[63] Liu, T., Fujita, T., Nakatsuka, T. and Kumamoto, E. (2008) Phospholipase A Activation Enhances Inhibitory Synaptic Transmission in Rat Substantia Gelatinosa Neurons. Journal of Neurophysiology, 99, 1274-1284. http://dx.doi.org/10.1152/jn.01292.2007

[64] Mason Jr., D.J., Lowe, J. and Welch, S.P. (1999) Cannabinoid Modulation of Dynorphin A: Correlation to Cannabinoid-Induced Antinociception. European Journal of Pharmacology, 378, 237-248. http://dx.doi.org/10.1016/S0014-2999(99)00479-3

[65] Kano, M., Ohno-Shosaku, T., Hashimotodani, Y., Uchigashima, M. and Watanabe, M. (2009) Endocannabinoid-Mediated Control of Synaptic Transmission. Physiological Reviews, 89, 309-380. http://dx.doi.org/10.1152/physrev.00019.2008

[66] Ohno-Shosaku, T. and Kano, M. (2014) Endocannabinoid-Mediated Retrograde Modulation of Synaptic Transmission. Current Opinion in Neurobiology, 29, 1-8. http://dx.doi.org/10.1016/j.conb.2014.03.017

[67] Hashimotodani, Y., Ohno-Shosaku, T., Yamazaki, M., Sakimura, K. and Kano, M. (2011) Neuronal Protease-Activated Receptor 1 Drives Synaptic Retrograde Signaling Mediated by the Endocannabinoid 2-Arachidonoylglycerol. Journal of Neuroscience, 31, 3104-3109. http://dx.doi.org/10.1523/JNEUROSCI.6000-10.2011 